"Mircea cel Batran" Naval Academy Scientific Bulletin, Volume XIX - 2016 - Issue 1

Published by "Mircea cel Batran" Naval Academy Press, Constanta, Romania // The journal is indexed in:

PROQUEST / DOAJ / DRJI / JOURNAL INDEX / I2OR / SCIENCE LIBRARY INDEX / Google Scholar / Crossref /

Academic Keys / ROAD Open Access / OAJI / Academic Resources / Scientific Indexing Services / SCIPIO

\title{
EXPERIMENTAL INVESTIGATION FOR FAULT DIAGNOSIS BASED ON FFT AND WAVELET TRANSFORM
}

\author{
Mihail PRICOP ${ }^{1}$ \\ lonuț-Cristian SCURTU² \\ Tiberiu PAZARA ${ }^{3}$ \\ Codruta PRICOP ${ }^{4}$ \\ Dinu ATODIRESEI ${ }^{5}$ \\ 1 Associate professor, PhD, „Mircea cel Batran” Naval Academy, Constanta, Romania, \\ mihail.pricop@anmb.ro \\ 2 LTJG (N) instr.Eng. , PhD, „Mircea cel Batran” Naval Academy, Constanta, Romania, \\ ionut.scurtu@anmb.ro \\ ${ }^{3}$ Lecturer, PhD, "Mircea cel Batran" Naval Academy, Constanta, Romania, tiberiu.pazara@anmb.ro \\ ${ }^{4}$ Associate Professor, Eng., PhD, Maritime University, Constanța, Romania, pricopcodruta@yahoo.com \\ ${ }^{5}$ Commander (N) Adv. Instructor, PhD, "Mircea cel Batran" Naval Academy, Constanta, Romania
}

\begin{abstract}
Belts are components of the mechanical systems of rotation commonly used for mechanical power transmission and changes in rotational speeds in the shafts. Various failures of the drive belts (foot shear, tooth wear, hollowed teeth, back cracks) are common in rotating machines and can cause economic losses. To increase efficiency, reliability and safety of the machines the use of new fault diagnosis techniques of belts, identification and classification is required. In this paper Fast Fourier Transform (FFT) and Wavelet transform complementary methods are used for fault monitoring of drive belts, analyzing in this way the limitations and advantages of using these methods. Experimental investigations for the fault diagnosis of drive belts are made using experimental platform and Bruel \& Kjaer equipment for measuring vibration and PULSE and MATLAB software for recorded signal processing. The results were analyzed and presented.
\end{abstract}

Keywords: fault diagnosis, drive belts, Fast Fourier Transform, Wavelet Transform.

\section{INTRODUCTION}

One of the common elements in the construction of rotating machines is the drive belt. Compared with other mechanical transmissions, transmission belts present a number of advantages: can be installed quickly, runs without noise, dampens shocks and vibrations, operates at high speeds, ensures protection against overloads, transmit loads away and several shafts simultaneously.

Disadvantages can include: limited load capacity, limited durability.

Drive belts are classified in many types according to: the shape of section, the shafts relative position, number of shafts driven simultaneously and transmission ratio.

V-belts are standardized according to the size of section, in two types: classic belts and narrow belts. V-belt transmission is characterized by greater load capacity. V-ribbed belts cross, leading to the increase of elasticity in the winding belt on the pulleys, makes bending stress decreasing and increasing the belt contact surface of the side walls of the pulley.

A pulley consists of the following parts: rim, spokes and hub or disc. Belts must meet the following main conditions: to be easy but ensuring the transmission of power; be well balanced; ensure a high friction coefficient, superior transverse stiffness and high wear resistance; support high peripheral speeds. Pulleys for classical V-belt transmission and narrow channels have standardized dimensions; minimum and maximum diameter of the pulleys is limited by belt type used.

To achieve friction between the belt and pulleys and avoid slipping is required belt tension. This can be done periodically by a suitable mounting, or continuously, during operation. Belts fail when they reach the limit fatigue after a period of two or three years of normal operation. Toothed belts may change the positioning and shape of teeth, yielding sleeve inadequate strength in operating conditions (tension installation erroneous transmission misalignment, small diameter wheel drive).

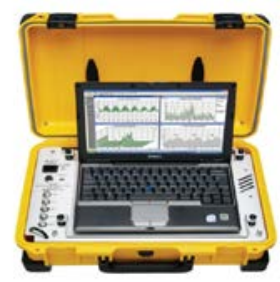

Fig.1. Machine Diagnostics Toolbox Type 9727 (Yellow Box) 


\begin{abstract}
"Mircea cel Batran" Naval Academy Scientific Bulletin, Volume XIX - 2016 - Issue 1
Published by "Mircea cel Batran" Naval Academy Press, Constanta, Romania /I The journal is indexed in: PROQUEST / DOAJ / DRJI / JOURNAL INDEX / I2OR / SCIENCE LIBRARY INDEX / Google Scholar / Crossref /

Academic Keys / ROAD Open Access / OAJI / Academic Resources / Scientific Indexing Services / SCIPIO
\end{abstract}

Development of diagnostic techniques $\mathrm{V}$-belts will avoid unexpected disposals thereof. Vibration belt has been investigated for several years, but remains a subject for analysis by specialists. Effectiveness fault diagnosis by using different techniques depends on the quality characteristics sought defect. Wavelet transform is a method that explores how changes frequency time, which facilitates detect and locate faults.

The paper presents the results of an experimental study for determining defects belts on CWT compared to FFT (fig.1 and 2). To achieve real results must choose a mother wavelet function that has a shape similar to the vibration caused by the malfunction signal chain.

2. CONTINUOUS WAVELET TRANSFORM (CWT)

Continuous wavelet transform (CWT) is used to divide continuous-time functions in a timefrequency representation of a signal based on wavelet transform. CWT based on a function $\psi(t)$ with $\mathrm{a}, \mathrm{b}>0$ and $a, b \in \mathbb{R}$ is calculated via

the integral below,

$$
X(a, b)=\frac{1}{|a|^{1 / 2}} \int_{-\infty}^{\infty} x(t) \bar{\psi}\left(\frac{t-b}{a}\right) d t
$$

where $\psi(t)$ is a continuous function in both the

time domain and the frequency domain called the mother wavelet and the over line represents operation of complex conjugate.

The scale factor a either dilates or compresses a signal. When the scale factor is relatively low, the signal is more contracted which in turn results in a more detailed resulting graph. However, the drawback is that low scale factor does not last for the entire duration of the signal. On the other hand, when the scale factor is high, the signal is stretched out which means that the resulting graph will be presented in less detail. Nevertheless, it usually lasts the entire duration of the signal.

In definition, the continuous wavelet transform is a convolution of the input data sequence with a set of functions generated by the mother wavelet. The convolution can be computed by using the Fast Fourier Transform (FFT). Normally, the output $X(a, b)$ is a real valued function except when the mother wavelet is complex. A complex mother wavelet will convert the continuous wavelet transform to a complex valued function. The power spectrum of the continuous wavelet transform can be represented by $|X(a, b)|^{2}$.

Continuous Wavelet Transform (CWT) is very efficient in determining the damping ratio of oscillating signals (e.g. identification of damping in dynamical systems). CWT is also very resistant to the noise in the signal.

Wavelet coefficients show how well a wavelet function is correlated with the signal, assuming that the energy signal and wavelet function wavelet coefficients are equal to 1 . The change signals will be strong and indicates the presence of defects.

\section{EXPERIMENTAL ANALYSIS}

Each recording was carried out on the period of time equal to 10 seconds which comprise 40960 samples in the frequency range $1-1600 \mathrm{~Hz}$. The sampling frequency is $1600 \mathrm{~Hz}$.

For PULSE software, the sampling frequency is 2.56 times higher than the frequency set to observe the sampling theorem and eliminate distortion due to aliasing.

The sampling frequency measurement is $2.56 \mathrm{x}$ $1600 \mathrm{~Hz}=4096 \mathrm{~Hz}$.

Measurements were carried out on three channels: channel 1 on the drive pulley bearing on the transverse direction (fig 2), Channels 2 and 4 on the bearing of the driven pulley belt transversely on respective horizontal vertical direction. To compare the behavior of the vibrations of the two bearings in the vicinity of the belt, all three signals have been recorded under the same conditions. The recorded signals were processed with software PULSE 12 and with MATLAB, presenting further processing from channel 2 to signal that presents the best characteristic for flawed diagnosis of the drive belt. 
"Mircea cel Batran" Naval Academy Scientific Bulletin, Volume XIX - 2016 - Issue 1

Published by "Mircea cel Batran" Naval Academy Press, Constanta, Romania // The journal is indexed in:

PROQUEST / DOAJ / DRJI / JOURNAL INDEX / I2OR / SCIENCE LIBRARY INDEX / Google Scholar / Crossref /

Academic Keys / ROAD Open Access / OAJI / Academic Resources / Scientific Indexing Services / SCIPIO

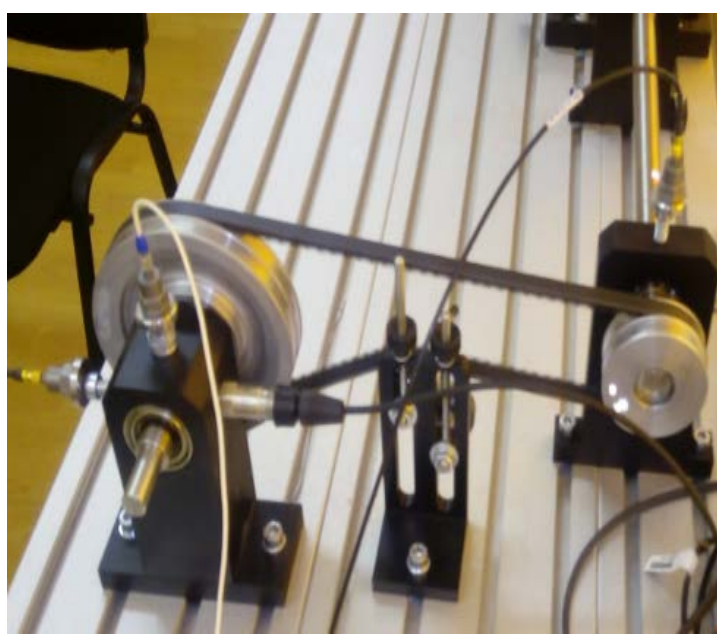

Fig.2. Sensor arrangement during measurements

Two test cases are realized using V-Belts of SPZ, which transmit rotary motion between two pulleys. The transmission characteristics are: $\mathrm{LB}=912$ $\mathrm{mm}$ belt length, belt pulley headed diameter $\mathrm{D}=$ $62.7 \mathrm{~mm}$.

Driveshaft speed and tachometer are measuring with three regimens were chosen by rotation $\mathrm{n}_{1}=$ $500 \mathrm{rpm}, \mathrm{n}_{2}=1500 \mathrm{rpm}$ and $\mathrm{n}_{3}=2500 \mathrm{rpm}$, corresponding $\mathrm{f}_{\mathrm{S} 1}=8.3 \mathrm{~Hz}$ frequencies, $\mathrm{f}_{\mathrm{S} 2}=$ $24,9 \mathrm{~Hz}$ and $\mathrm{f}_{\mathrm{s} 3}=415 \mathrm{~Hz}$. Transmission belt frequencies for the three modes of rotation is calculated by formula:

$$
f_{B}=\frac{\pi \cdot D \cdot n}{60-L_{B}}
$$

to give the values $\mathrm{f}_{\mathrm{B} 1}=1.8 \mathrm{~Hz}, \mathrm{f}_{\mathrm{B} 2}=5.4 \mathrm{~Hz}$ and $\mathrm{f}_{\mathrm{B} 3}$ $=9 \mathrm{~Hz}$.

It is now a defective belt experimental stand type wear. All tooth defects will appear in the time record intevals: $T_{\mathrm{f} 1}=0,55 \mathrm{~s}, \mathrm{~T}_{\mathrm{f} 2}=0,185 \mathrm{~s}$ and $\mathrm{T}_{\mathrm{f} 3}=$ $0,111 \mathrm{~s}$ or translated in samples $\mathrm{N}_{\mathrm{f} 1}=2256$ samples, $\mathrm{N}_{\mathrm{t} 2}=758$ samples and $\mathrm{N}_{\mathrm{t} 3}=455$ samples.

The platform used in the experiment is shown in fig. 1 and the details at the belt drives in fig. 2 .

Measurements were performed using Bruel \& Kjaer equipment type 9727. Accelerometers connected to the Machine Diagnostics Toolbox year 9727 which has integrated PULSE 12 laptop with Bruel \& Kjaer software.

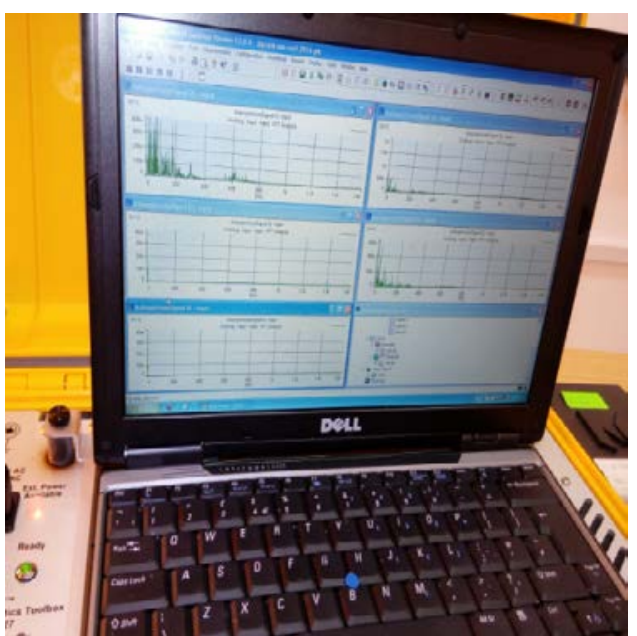

Fig.3. Pulse Labshop image during test measurements

\section{RESULTS AND DISCUSSION}

In fig. 4-9 are given FFT for situations when the V-belt drive system is flawless and defect type case with tooth wear. Analyzing that spectrum is observed comprise common shaft bearing frequencies, belt frequency and their harmonics. Modified spectral characteristics, by overlapping vibrating and the presence of non-stationary vibration in the frequency spectrum, certain components mask just those frequencies which cause defects.

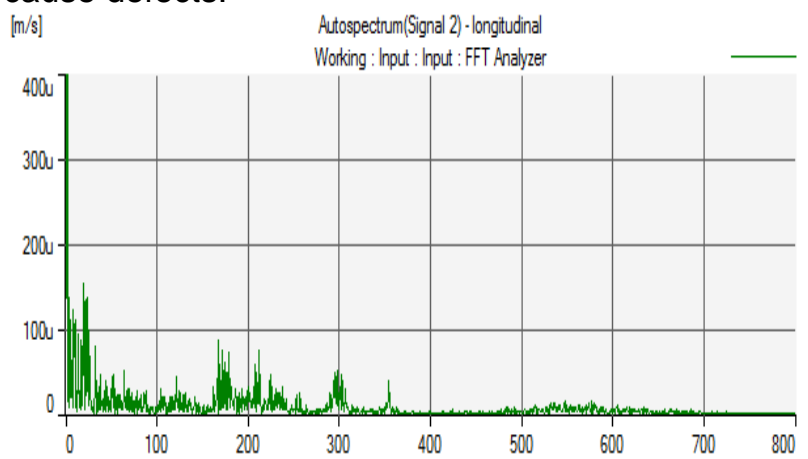

Fig.4. FFT for signal 2 tested with belt defect at $500 \mathrm{rpm}$

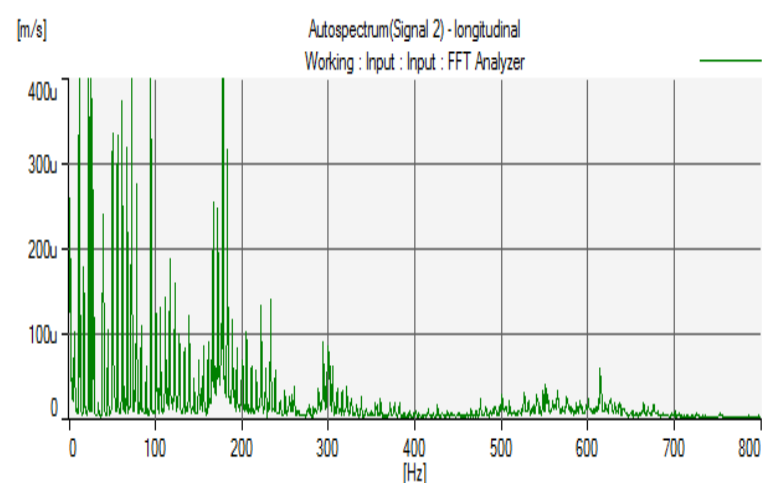

Fig.5. FFT for signal 2 tested with belt defect at $1500 \mathrm{rpm}$ 
"Mircea cel Batran" Naval Academy Scientific Bulletin, Volume XIX - 2016 - Issue 1

Published by "Mircea cel Batran" Naval Academy Press, Constanta, Romania // The journal is indexed in: PROQUEST / DOAJ / DRJI / JOURNAL INDEX / I2OR / SCIENCE LIBRARY INDEX / Google Scholar / Crossref / Academic Keys / ROAD Open Access / OAJI / Academic Resources / Scientific Indexing Services / SCIPIO

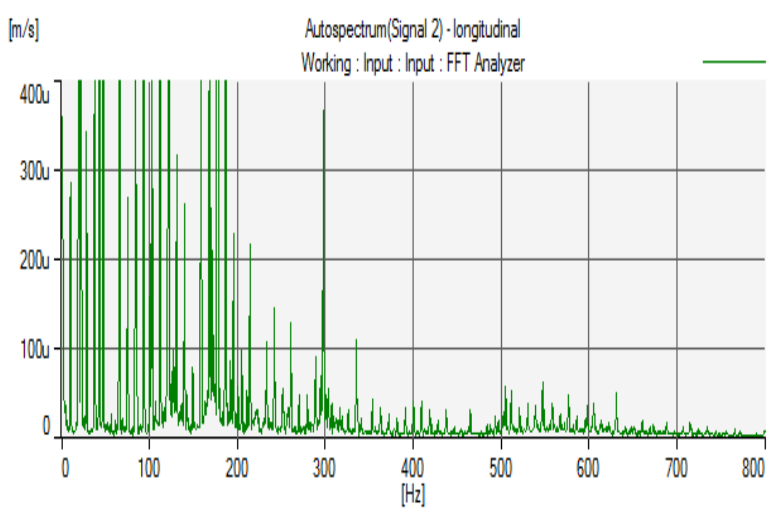

Fig.6. FFT for signal 2 tested with belt defect at $2500 \mathrm{rpm}$

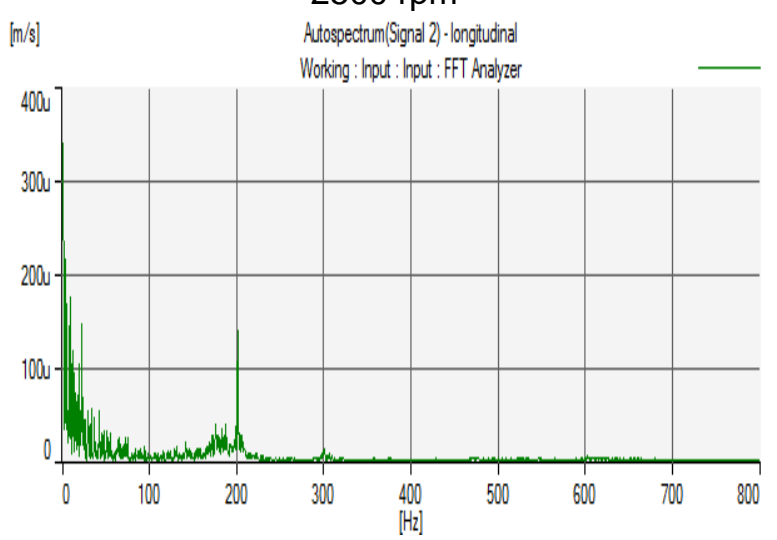

Fig.7. FFT for signal 2 tested (without belt defect)

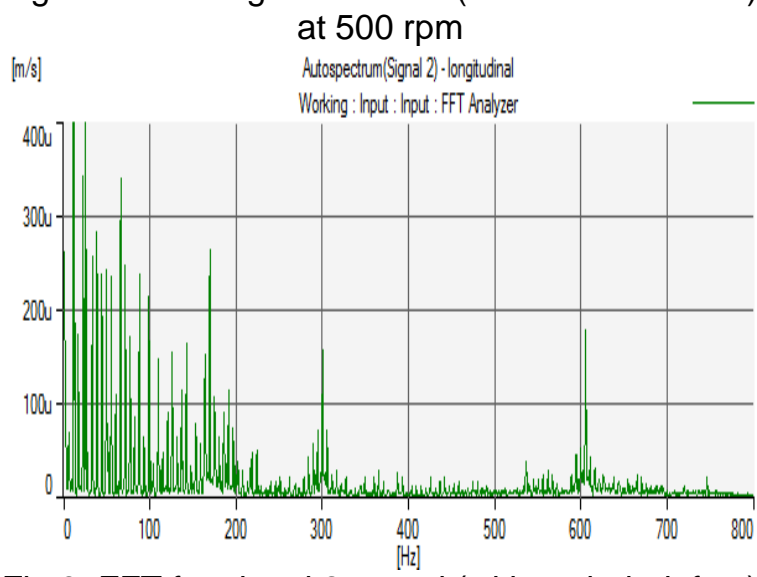

Fig.8. FFT for signal 2 tested (without belt defect) at $1500 \mathrm{rpm}$

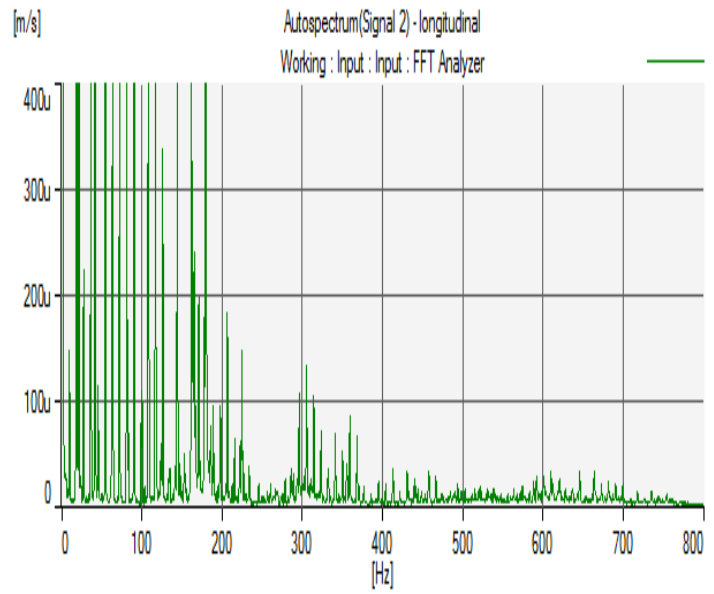

Fig.9. FFT for signal 2 tested (without belt defect) at $2500 \mathrm{rpm}$

The use of complex signal processing techniques registered under unsteady, eliminating background noise, signal decomposition into a low frequency and high frequency compact wavelet series determines performance improvement diagnostic trouble in the components of the rotation system.

So in this sense, the paper proposes to use CWT method for diagnosing faults in transmission belt system.

The recorded signal is meshed in 2048 samples to $1500 \mathrm{rpm}$ and $2500 \mathrm{rpm}$ or 4096 samples at $500 \mathrm{rpm}$, so there is that time period covering periods of occurrence of defects in the belt. We have used two types of mother wavelet: Haar wavelet function (fig 10-16) and Morlet (fig 17-19).

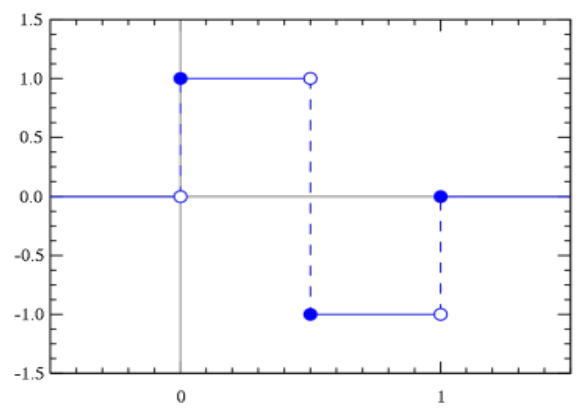

Fig.10. Haar mother wavelet function

Standard Haar wavelet

$$
\psi(t)=\left\{\begin{array}{cc}
1, & 0 \leq t \leq \frac{1}{2}, \\
-1, & \frac{1}{2} \leq t \leq 1, \\
0 & \text { otherwiswe }
\end{array}\right.
$$

and $\psi_{j k}(x)=\psi\left(2^{j} x-k\right)$,

for $\mathrm{j}$ a non negative integer and $0 \leq k \leq 2^{j}-1$.

Wavelet coefficients (figures 11-16) represent in shades of color diagram time I 
"Mircea cel Batran" Naval Academy Scientific Bulletin, Volume XIX - 2016 - Issue 1

Published by "Mircea cel Batran" Naval Academy Press, Constanta, Romania /I The journal is indexed in: PROQUEST / DOAJ / DRJI / JOURNAL INDEX / I2OR / SCIENCE LIBRARY INDEX / Google Scholar / Crossref /

Academic Keys / ROAD Open Access / OAJI / Academic Resources / Scientific Indexing Services / SCIPIO

samples scale generates a lot of information about the defects, location and extent of damage. After decomposition of the signal at different scales, each feature appears only a single component scale and location of the signal.

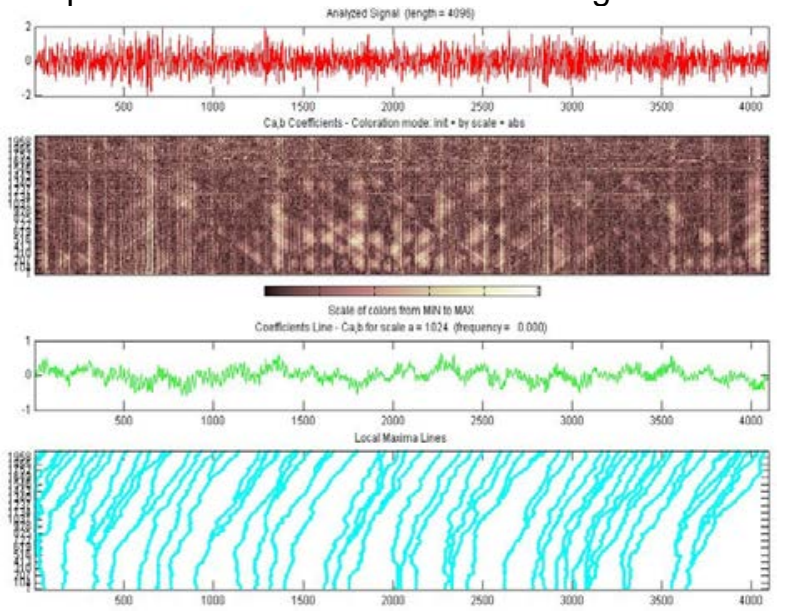

Fig.11. CWT_haar signal 2 for 4096 samples, without belt defect, at 500 rpm

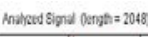
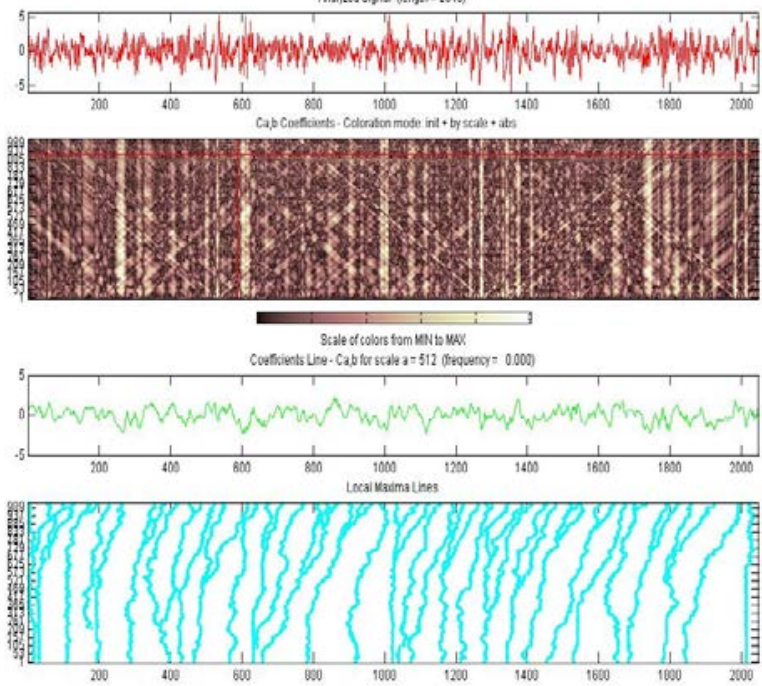

Fig.12. CWT_haar signal 2 for 2048 samples, without belt defect, at $1500 \mathrm{rpm}$
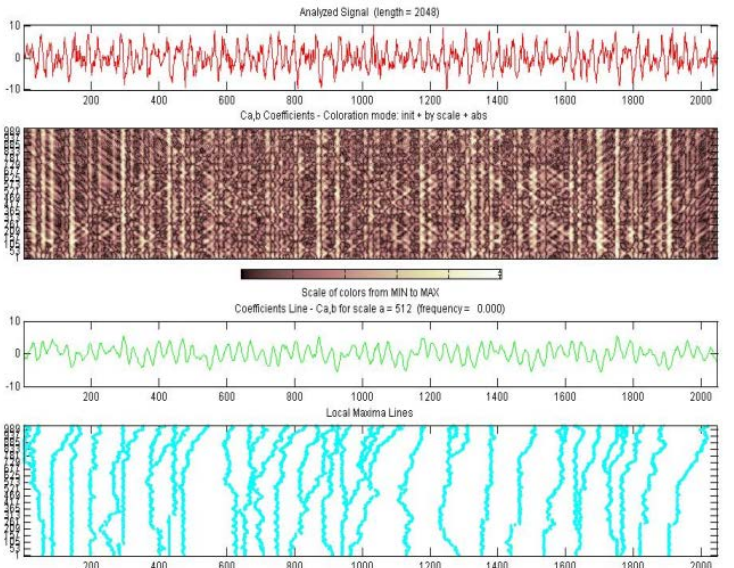

Fig.13. CWT_haar signal 2 for 2048 samples, without belt defect, at $2500 \mathrm{rpm}$
Compared are presented CWT rotation system with belt defect in the same speeds.
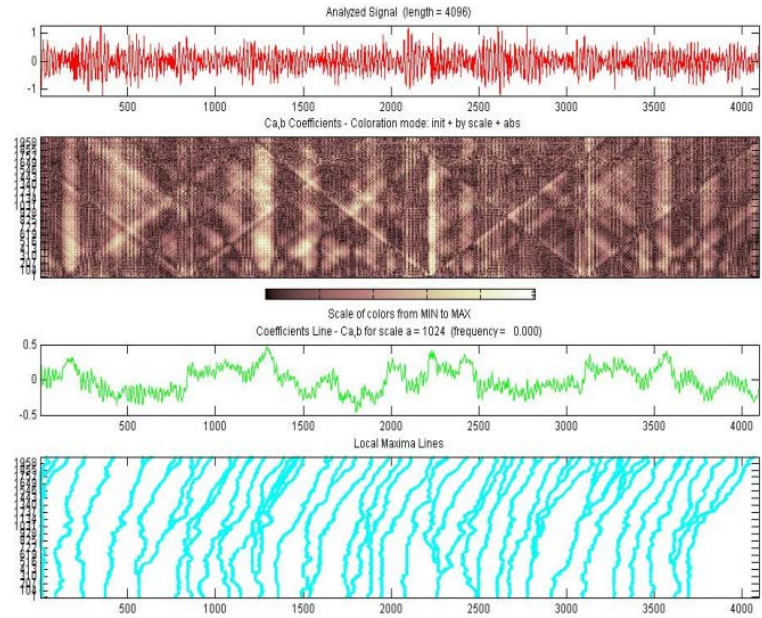

Fig.14. CWT_haar signal 2 for 4096 samples, with belt defect, at $500 \mathrm{rpm}$

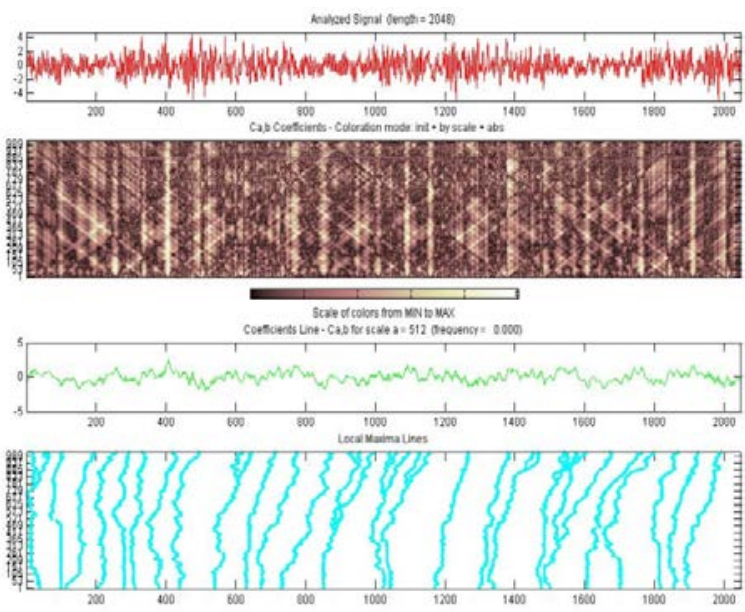

Fig.15. CWT_haar signal 2 for 2048 samples, with belt defect, at $1500 \mathrm{rpm}$
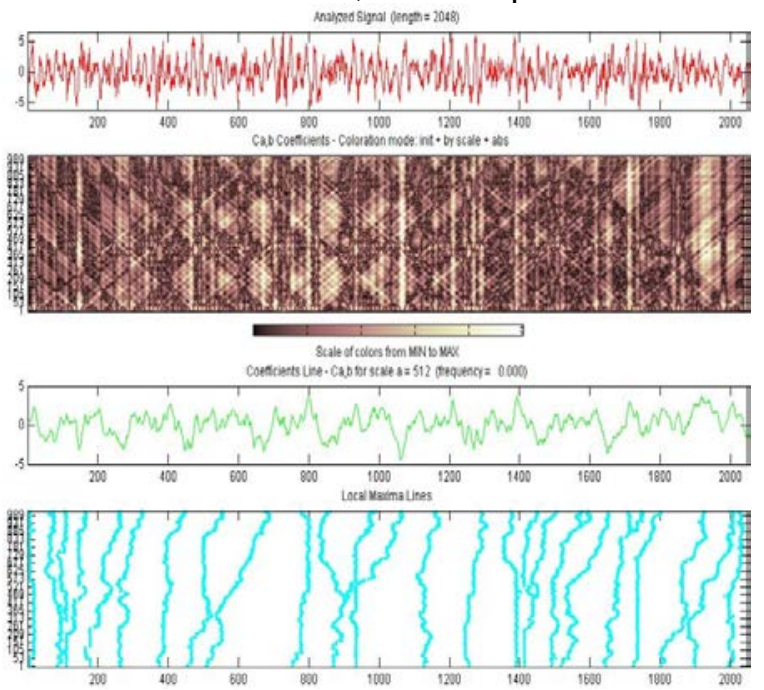

Fig.16. CWT haar signal 2 for 2048 samples, with belt defect, at $2500 \mathrm{rpm}$ 
"Mircea cel Batran" Naval Academy Scientific Bulletin, Volume XIX - 2016 - Issue 1

Published by "Mircea cel Batran" Naval Academy Press, Constanta, Romania // The journal is indexed in: PROQUEST / DOAJ / DRJI / JOURNAL INDEX / I2OR / SCIENCE LIBRARY INDEX / Google Scholar / Crossref /

Academic Keys I ROAD Open Access / OAJI / Academic Resources / Scientific Indexing Services / SCIPIO

For speed of $500 \mathrm{rpm}$ and the two situations with and without fault in transmission belts are shown to compare CWT using Morlet mother wavelet function.

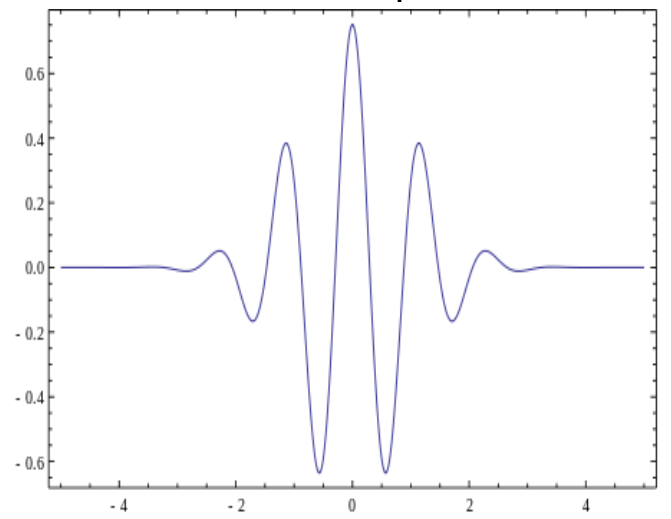

Fig.17. Morlet mother wavelet function
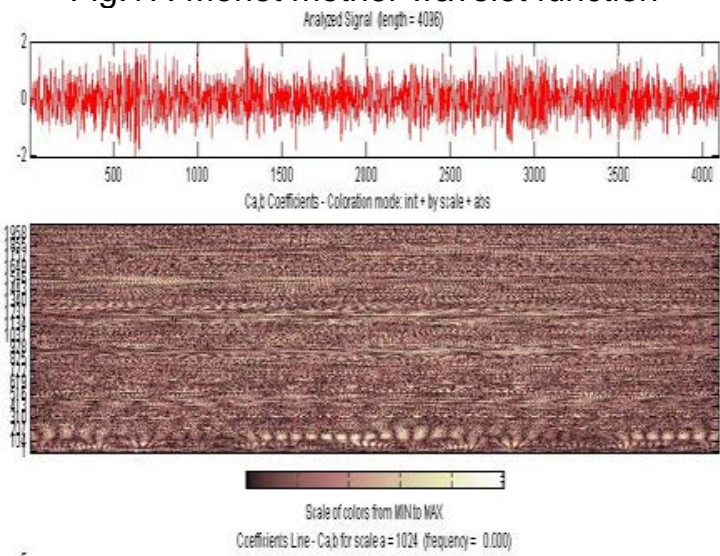

Fig.18. CWT_morl signal 2 for 4096 samples, without belt defect, at $500 \mathrm{rpm}$
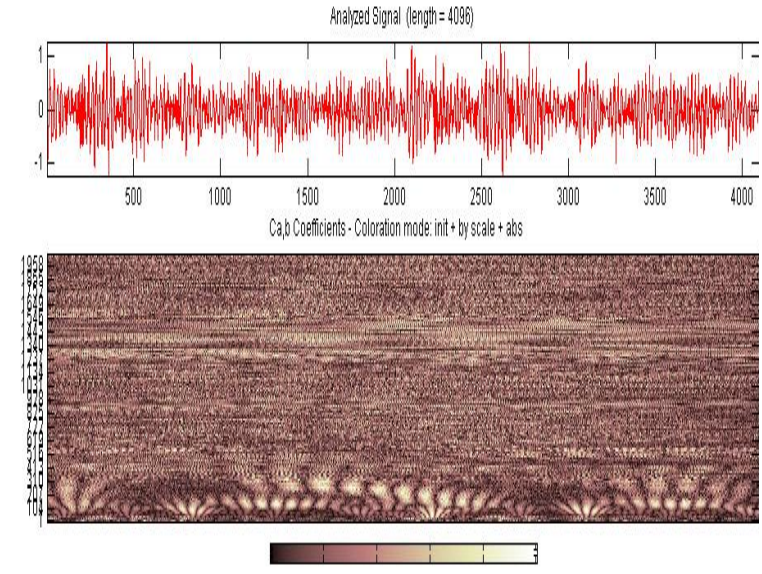

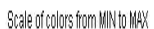

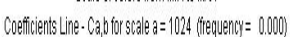

Fig.19. CWT morl signal 2 for 4096 samples, with belt defect, at $500 \mathrm{rpm}$

\section{CONCLUSIONS}

This article presents a study on the use of CWT in detecting faults in transmission belt, an important element in a gearing. For both normal machinery and with defect in the belt the signals were obtained experimentally on a stand diagnose malfunctions.

In the first part of the study was demonstrated once again that FFT cannot be used in non-stationary signal analysis, if the defect in the drive belt, being successfully used in stationary signal analysis.

CWT is useful in detecting the defect is determined by the power of this tool to use function Local Maxima Lines, which by exploiting gradient information in the scale-location demonstrates once again effective for detailed feature extraction (singularities and discontinuities) signal.

By comparing rational selection of study shows the importance of mother wavelet function, which can greatly affect the outcome of fault detection. Charts of the features of the scale-time, Maxima Lines Local representation is seen as Haar function is well chosen to determine faults in the transmission belt. Using comparative Morlet mother wavelet in detecting faults in the belt, demonstrates the effectiveness of Haar function.

\section{BIBLIOGRAPHY}

[1] Mikalauskas, R. and Volkovas, V. Analysis of the dynamics of a defective V-belt and diagnostic possibilites. Proc. IMechE, Systems and Control Engineering, 20:145-153, 2006.

[2] H. Yamashina, S. Okumura and I. Kawai, "Development of a diagnosis technique for failures of V-belts by a cross-spectrum method and a discriminant function approach," J. Intell. Manuf., vol. 7, no. 1, pp. 85-93, 1996.

[3] Zheng, H., Li, Z., Chen X., Gear Fault Diagnosis Based on Continous Wavelet Transform, Mechanical Systems and Signal Proccesing, Vol. 16, No. (2-3), pp. 447-457, 2002 
"Mircea cel Batran" Naval Academy Scientific Bulletin, Volume XIX - 2016 - Issue 1

Published by "Mircea cel Batran" Naval Academy Press, Constanta, Romania /I The journal is indexed in: PROQUEST / DOAJ / DRJI / JOURNAL INDEX / I2OR / SCIENCE LIBRARY INDEX / Google Scholar / Crossref I Academic Keys / ROAD Open Access / OAJI / Academic Resources / Scientific Indexing Services / SCIPIO

[4] Li Li, Liangsheng Qu, Xianghui Liao, Haar wavelet for machine fault diagnosis, Mechanical System and Signal Processing 21 (2007), pp 1773-1786.

[5] Dinu Atodiresei, Vergil Chitac, Mihail Pricop, Florin Nicolae, Alecu Toma, Ionut Scurtu „NS MIRCEA" compartments classification and noise analysis of the marine environment by acoustic emissions. "Mircea cel Batran" Naval Academy Scientific Bulletin, Volume XVII - 2015 - Issue 1, pag. 13-17, Published by "Mircea cel Batran" Naval Academy Press, Constanta, Romania, ISSN 1454-864X (Category B/CNCS)// The journal is indexed in PROQUEST

[6] Pricop M., Pazara T., Pricop C., Atodiresei D, Scurtu I.-C., Oncica V., Passive acoustic underwater noise measurements in Constanta port area ,Mircea cel Batran" Naval Academy Scientific Bulletin, Volume XVIII 2015 - Issue 2, pag. 8-13, Published by "Mircea cel Batran" Naval Academy Press, ISSN 1454-864X (Category B/CNCS), Sea-Conf 2015 1st International Conference Constanta

[7] Michel Misiti, Georges Oppenheim, Jean Michel Poggi, Wavelet Toolbox- User's Guide, The MathWorks, USA, 2006. 